\title{
Cloud detection over snow and ice with oxygen A- and B-band observations from the Earth Polychromatic Imaging Camera (EPIC)
}

\author{
Yaping Zhou ${ }^{1,2}$, Yuekui Yang ${ }^{1}$, Meng Gao ${ }^{1,3}$, and Peng-Wang Zhai ${ }^{4}$ \\ ${ }^{1}$ NASA Goddard Space Flight Center, Greenbelt, MD, USA \\ ${ }^{2}$ The Joint Center for Earth Systems Technology, University of Maryland Baltimore County, Baltimore, MD, USA \\ ${ }^{3}$ SSAI/NASA Goddard Space Flight Center, Ocean Ecology Laboratory, Greenbelt, MD, USA \\ ${ }^{4}$ The Joint Center for Earth Systems Technology, Department of Physics, University of Maryland Baltimore County, \\ Baltimore, MD 21250, USA
}

Correspondence: Yaping Zhou (yaping.zhou-1@ nasa.gov)

Received: 14 September 2019 - Discussion started: 21 October 2019

Revised: 27 January 2020 - Accepted: 21 February 2020 - Published: 1 April 2020

\begin{abstract}
Satellite cloud detection over snow and ice has been difficult for passive remote sensing instruments due to the lack of contrast between clouds and cold/bright surfaces; cloud mask algorithms often heavily rely on shortwave infrared (IR) channels over such surfaces. The Earth Polychromatic Imaging Camera (EPIC) on board the Deep Space Climate Observatory (DSCOVR) does not have infrared channels, which makes cloud detection over snow and ice surfaces even more challenging. This study investigates the methodology of applying EPIC's two oxygen absorption band pair ratios in the A band $(764,780 \mathrm{~nm})$ and $B$ band $(688,680 \mathrm{~nm})$ for cloud detection over the snow and ice surfaces. We develop a novel elevation and zenith-angle-dependent threshold scheme based on radiative transfer model simulations that achieves significant improvements over the existing algorithm. When compared against a composite cloud mask based on geosynchronous Earth orbit (GEO) and low Earth orbit (LEO) sensors, the positive detection rate over snow and ice surfaces increased from around $36 \%$ to $65 \%$ while the false detection rate dropped from $50 \%$ to $10 \%$ for observations of January 2016 and 2017. The improvement in July is less substantial due to relatively better performance in the current algorithm. The new algorithm is applicable for all snow and ice surfaces including Antarctic, sea ice, highlatitude snow, and high-altitude glacier regions. This method is less reliable when clouds are optically thin or below $3 \mathrm{~km}$ because the sensitivity is low in oxygen band ratios for these cases.
\end{abstract}

\section{Introduction}

The Earth Polychromatic Imaging Camera (EPIC) on board the Deep Space Climate Observatory (DSCOVR) was launched in 2015. The unique orbit of DSCOVR allows the EPIC instrument to take continuous measurements of the entire sunlit side of the Earth from the nearly backscattering direction (scattering angles between 168.5 and $175.5^{\circ}$ ) from the first Lagrangian (L1) point of the Earth-Sun orbit, approximately 1.5 million kilometers away. The EPIC instrument has 10 narrow spectral channels in the ultraviolet (UV) and visible/near-infrared (Vis/NIR) $(317-780 \mathrm{~nm})$ spectral range that enable retrieval of atmospheric ozone, cloud, and surface vegetation information. The focal plane of the EPIC system is a 2048 pixel $\times 2048$ pixel charge-coupled device (CCD) array that covers the entire disk with a nadir resolution of $8 \mathrm{~km}$. However, due to the limited transmission capacity, all channels except the $443 \mathrm{~nm}$ channel are reduced to $1024 \times 1024$ arrays through onboard processing and interpolated back to full resolution after being downlinked. The operation of the instrument and the downlink speed limit the temporal frequency of measurements to be approximately once every 1.5 and $2.5 \mathrm{~h}$ in boreal winter and summer, respectively. Detailed descriptions of the EPIC instrument can be found in Herman et al. (2018), Marshak et al. (2018), and Yang et al. (2019).

The EPIC cloud products, including cloud mask (CM), cloud effective pressure (CEP), cloud effective height (CEH), 
and cloud optical thickness (COT), are developed with fewer spectral channels compared with many spectroradiometers currently on board the polar and geostationary satellites (Yang et al., 2019). For example, the Moderate-resolution Imaging Spectroradiometer (MODIS) cloud algorithm uses simultaneous two-channel retrievals of COT and cloud effective radius (CER) separately for water and ice clouds, with the cloud phase predetermined by more spectral tests. Since EPIC does not have a particle-size-sensitive channel, and has limited capability to determine the cloud phase, the EPIC COT retrieval uses a single channel and derives two sets of COT, one for assumed ice phase and one for assumed liquid phase, each with fixed CER (Yang et al., 2019; Meyer et al., 2016). CEP is derived based on two oxygen $\left(\mathrm{O}_{2}\right)$ band pairs, each consisting of an absorption and a reference channel. The A-band absorption channel is centered at $764 \mathrm{~nm}$ with a full width at half maximum (FWHM) of $1.02 \mathrm{~nm}$, and its reference channel is centered at $780 \mathrm{~nm}$ with a FWHM of $1.8 \mathrm{~nm}$. The B band's absorption channel is centered at $688 \mathrm{~nm}$ with a FWHM of $0.84 \mathrm{~nm}$, and its reference channel is centered at $680 \mathrm{~nm}$ with a FWHM of $1.6 \mathrm{~nm}$ (Marshak et al., 2018). The $\mathrm{O}_{2}$ absorption bands are sensitive to cloud height because the presence of clouds, especially thick clouds, reduces the absorbing air mass that light travels through; hence, the ratio of the absorbing and reference bidirectional reflectance functions (BRFs) becomes larger. Since $\mathrm{O}_{2}$ absorption at $764 \mathrm{~nm}$ is stronger than at $688 \mathrm{~nm}$, the A-band ratio has higher sensitivity than the B-band ratio (Yang et al., 2013).

Satellite cloud detections are usually based on the contrast between clouds and the underlying Earth surface. Clouds are generally higher in reflectance and lower in temperature than the surface, which makes simple threshold approaches in the visible and infrared window channels effective in cloud detection (e.g., Saunders and Kriebel, 1988; Rossow and Garder, 1993; Yang et al., 2007; Ackerman et al., 2010). However, there are many situations when simple visible and infrared threshold tests are not able to separate clouds from surface or from heavy atmospheric aerosols such as dust and smoke. The contrasts between clouds and surface are weak in the visible channels when the surface is bright and weak in the IR channels when the surface temperature is very low or the cloud is very low in height. Additionally, partially cloudy pixels due to small-scale cumulus or cloud edges also increase the detection difficulty. The official MODIS CM algorithm uses more than 20 spectral channels to detect clouds in various situations. In particular, it heavily relies on shortwave infrared channels at $1.38,1.6$, and $2.1 \mu \mathrm{m}$ and thermal channels at 11 and $13.6 \mu \mathrm{m}$ for cloud detection over snow and ice (Frey et al., 2008; Ackerman et al., 2010)

The lack of infrared and near-infrared channels in EPIC makes cloud detection very challenging, especially over snow and ice surfaces. The current EPIC CM algorithm adopts a general threshold method, which uses two sets of spectral tests for each of the three scene types: ocean, land, and ice/snow (Yang et al., 2019). Over ocean, the 680 and
$780 \mathrm{~nm}$ channels are used for cloud detection, because clouds and the sea surface contrast well in both channels. Over land, because of large variations in surface reflectivity at 680 and $780 \mathrm{~nm}$, these two channels can no longer be used alone for cloud detection. Instead, the algorithm uses the $388 \mathrm{~nm}$ channel and the A-band reflectivity ratio, i.e., $R_{764} / R_{780}$ for cloud detection. The $388 \mathrm{~nm}$ channel is used because of its low reflectivity over land surfaces. The A-band ratio is used based on the same mechanism as the cloud height retrieval because clouds reduce $\mathrm{O}_{2}$ band absorption by increasing the height of the effective reflective layer. Thus, the A-band ratio of a cloudy pixel is expected to be higher than that of a clear pixel in an otherwise identical situation. The A-band ratio is selected for use over the land surface because it has higher sensitivity than the B-band ratio. Over snow- and ice-covered regions, the $\mathrm{O}_{2} \mathrm{~A}$ - and $\mathrm{B}$-band ratios are used for cloud detection since the contrast between surface and clouds is small in the visible and UV channels. Evaluations using the collocated cloud retrievals from other sensors show that the EPIC CM performs very well in general. The EPIC CM has an overall $80.2 \%$ accuracy rate and $85.7 \%$ correct cloud detection rate (accuracy and correct cloud detection rate are defined in Sect. 5), but a large discrepancy is found over the snow- or ice-covered surfaces where the EPIC algorithm significantly underestimates cloud fraction, especially over iceand snow-covered Antarctica (Yang et al., 2019). One of the reasons is that the current algorithm uses empirically derived fixed A-band and B-band ratio thresholds without considering the photon path changes due to Sun/sensor geometry and surface elevation.

The current work aims to improve EPIC cloud masking through a better understanding of the variability of the $\mathrm{O}_{2}$ band ratios under various clear and cloudy conditions over snow and ice surfaces. Radiative transfer model simulations and observed reflectance will be examined to derive dynamic thresholds for the $\mathrm{O}_{2}$ band ratios so that the new algorithm is applicable to all snow and ice surfaces, i.e., Antarctica, Greenland, snow in high latitude, and glaciers over high mountains.

To compute radiation fluxes from EPIC and NISTAR instruments on board the DSCOVR satellite (Su et al., 2018, 2020), the Clouds and the Earth's Radiant Energy System (CERES) team at the NASA Langley Research Center created a composite cloud product from geosynchronous Earth orbit (GEO) and low Earth orbit (LEO) satellites by projecting the GEO/LEO retrievals to the EPIC grid at each EPIC observing time (Khlopenkov et al., 2017). The procedure ensures that every EPIC image/pixel has a corresponding GEO/LEO composite image/pixel with approximately the same size and observation time. The LEO satellites include NASA Terra and Aqua MODIS and NOAA AVHRR, while geosynchronous satellite imagers include the Geostationary Operational Environmental Satellites (GOES) operated by NOAA, Meteosat satellites by EUMETSAT, and Multifunctional Transport Satellites (MTSAT) and Himawari-8 satel- 
lites operated by the Japan Meteorological Agency (JMA). Compared to EPIC, the GEO/LEO sensors are usually better equipped for cloud detection over snow and ice. For this study, the GEO/LEO cloud mask is used as a reference for EPIC threshold finding and result comparison purposes. The time differences between the GEO/LEO and the EPIC observations are included in the product files. To limit uncertainties, we only use pixels where the GEO/LEO and EPIC observations are within $5 \mathrm{~min}$ of each other.

The remainder of the paper is organized as follows: Sect. 2 provides an analytical discussion on the relationship between the $\mathrm{O}_{2}$ band ratios with the relative air mass and surface elevation. Section 3 conducts sensitivity studies through radiative transfer modeling and describes the threshold derivation procedure using the model simulations. Section 4 describes the new cloud mask algorithm for the EPIC instrument over snow and ice. Section 5 reports on the new algorithm validation. Finally, Sect. 6 provides a brief summary and discussion.

\section{An analytical guide with monochromatic radiative transfer}

Oxygen absorption has been applied to remote sensing of cloud and aerosol extensively (e.g., Grechko et al., 1973; Fischer and Grassl, 1991; Min et al., 2004; Stammes et al., 2008; Wang et al., 2008; Vasilkov et al., 2008; Ferlay et al., 2010; Koelemeijer et al., 2001; Yang et al., 2013; Ding et al., 2016; Richardson et al., 2019). The underlying physics is based on the well-known gaseous absorption of well-mixed atmospheric $\mathrm{O}_{2}$. Changes in observed radiance in the $\mathrm{O}_{2}$ band are expected to contain information on how clouds or atmospheric aerosols interrupt the normal absorption photon path and/or provide additional scattering at different vertical levels. The cloud detection using the $\mathrm{O}_{2}$ absorption band ratios is based on the fact that clouds decrease the photon path length within the atmosphere. Clouds reduce the oxygen absorption optical thickness while their impact on the nearby reference channels is negligible. As a result, holding everything else equal, the BRF ratios between the absorption and the reference channels are expected to be larger for cloudy skies than clear skies. In reality, photon paths can be very complicated: Yang et al. (2013) listed six pathways for a photon to reach the sensor. To simplify the discussion, we focus only on completely clear or cloudy cases. To determine a threshold for separating clear sky and cloudy sky, the first step is to understand factors that affect the clear-sky $\mathrm{O}_{2}$ band ratios. The second step is to understand how $\mathrm{O}_{2}$ band ratios change with the presence of different kinds of clouds. This step helps determine where thresholds can be drawn between clear skies and cloudy skies and what kind of sensitivity or uncertainty can be expected with this method.

The radiances entering the sensor consist of many components, including sunlight directly reflected by clouds, aerosols, and surfaces, as well as Rayleigh scattering through single- and multiple-scattering processes. Rayleigh optical thicknesses at the oxygen A- and B-band regions are about 0.02 and 0.04 , respectively. Hence, for a clear sky over a bright surface, we can neglect the contribution of single and multiple scattering. Thus, the monochromatic BRF at the top of atmosphere can be related to the column optical depth via Beer's law as

$$
\begin{aligned}
& R_{\mathrm{abs}}=T_{\mathrm{abs}}^{\mathrm{dn}} \times \alpha_{\mathrm{abs}} \times T_{\mathrm{abs}}^{\mathrm{up}}=\alpha_{\mathrm{abs}} e^{-\left(\tau(z)+\tau_{\mathrm{ray}}(z)\right)\left(\frac{1}{\mu}+\frac{1}{\mu_{0}}\right),} \\
& R_{\mathrm{ref}}=T_{\mathrm{ref}}^{\mathrm{dn}} \times \alpha_{\mathrm{ref}} \times T_{\mathrm{ref}}^{\mathrm{up}}=\alpha_{\mathrm{ref}} e^{-\tau_{\mathrm{ray}}(z)\left(\frac{1}{\mu}+\frac{1}{\mu_{0}}\right),} \\
& m=\frac{1}{\mu}+\frac{1}{\mu_{0}}=\frac{1}{\cos \theta}+\frac{1}{\cos \theta_{0}},
\end{aligned}
$$

where $R_{\mathrm{abs}}$ and $R_{\text {ref }}$ are the BRFs for the oxygen band and its reference band, respectively. The BRF at the top of the atmosphere is a product of downward transmittance $\left(T^{\mathrm{dn}}\right)$, spectral surface reflection albedo $\alpha$, and upward transmittance $\left(T^{\text {up }}\right) . \tau$ and $\tau_{\text {ray }}$ are optical thickness values due to $\mathrm{O}_{2}$ absorption and Rayleigh scattering at nadir, respectively, and are functions of surface elevation $Z . m$ is the total air mass accounting for the slant path for both incoming $\left(T^{\mathrm{dn}}\right)$ and reflected light $\left(T^{\mathrm{up}}\right)$. The absorption channels are subject to both absorption and Rayleigh scattering, while the reference channels only incur Rayleigh scattering. The ratio of $R_{\mathrm{abs}}$ and $R_{\text {ref }}$ led to the cancellation of Rayleigh scattering and surface albedo since the two channels are very close, such that

$\frac{R_{\mathrm{abs}}}{R_{\mathrm{ref}}}=e^{-\tau(z)\left(\frac{1}{\mu}+\frac{1}{\mu_{0}}\right)}=e^{-\tau(z) \times m}$.

The absorption optical thickness at a given location decreases exponentially with surface elevation following the approximate relationship in Eq. (5) (Petty, 2006):

$\tau(z)=K_{\mathrm{a}} w_{1} \rho_{0} H \exp \left(-\frac{Z}{H}\right)=c \times \exp \left(-\frac{Z}{H}\right)$.

Here $H$ is the scale height; and $K_{\mathrm{a}}, w_{1}$, and $\rho_{0}$ are the mass absorption coefficient, mixing ratio of oxygen, and density of air at sea level, respectively. $c=K_{\mathrm{a}} w_{1} \rho_{0} H$ and can be assumed constant for our problem. To relate the $\mathrm{O}_{2}$ band ratios directly to surface elevation and zenith angles in two separate terms, we take a double logarithm on both sides of Eq. (4) and substitute $\tau$ with Eq. (5), which leads to

$\ln \left(\frac{R_{\mathrm{abs}}}{R_{\mathrm{ref}}}\right)=-c \times \exp \left(-\frac{Z}{H}\right) \times m$.

Define

$\mathrm{d} b \ln \left(\frac{R_{\mathrm{abs}}}{R_{\text {ref }}}\right)=\ln \left\{-\ln \left(\frac{R_{\mathrm{abs}}}{R_{\text {ref }}}\right)\right\}$.

We have

$\mathrm{d} b \ln \left(\frac{R_{\mathrm{abs}}}{R_{\mathrm{ref}}}\right)=\ln c-\frac{Z}{H}+\ln m$. 
Here $\mathrm{d} b \ln$ refers to the double logarithm, and the minus sign before the second logarithm function is added to avoid negative values. Equation (8) decouples the effect of elevation and zenith angles in $\mathrm{d} b \ln \left(\frac{R_{\text {abs }}}{R_{\text {ref }}}\right)$, which allows estimation of coefficients in Eq. (8) with simple multivariate linear regression using two independent terms, $Z$ and $\ln m$ :

$\mathrm{d} b \ln \left(\frac{R_{\mathrm{abs}}}{R_{\mathrm{ref}}}\right) \approx c_{0}+c_{1} Z+c_{2} \ln m$.

Here $c_{0}, c_{1}$, and $c_{2}$ will be regression coefficients and can be used to predict the expected $\mathrm{d} b \ln \left(\frac{R_{\text {abs }}}{R_{\text {ref }}}\right)$. Once $\mathrm{d} b \ln \left(\frac{R_{\text {abs }}}{R_{\text {ref }}}\right)$ is solved, the $\mathrm{O}_{2}$ band ratios can be derived with Eq. (10):

$$
\frac{R_{\mathrm{abs}}}{R_{\text {ref }}}=\exp \left(-\exp \left(\mathrm{d} b \ln \left(\frac{R_{\mathrm{abs}}}{R_{\text {ref }}}\right)\right)\right) .
$$

The above derivation shows that the clear-sky $\mathrm{O}_{2}$ band ratios can be analytically predicted using surface elevation and zenith angles. Of course, many approximations have been used, such as the cancellation of Rayleigh extinction and surface BRF for the pair channels and constant absorption scale height. Due to large surface albedo, contributions of Rayleigh scattering are also neglected. The contribution of Rayleigh scattering in the reflectance is about $0.01-0.02$, and this may cause an uncertainty of $1 \%$ to $2 \%$ in the band ratio for bright surfaces. In cases of dark surfaces such as oceans, the surface albedo is so small $(\sim 0.05)$ that the Rayleigh scattering starts to dominate the observed reflectance, and the simple equations derived here will result in a large bias. However, with relatively large albedos (around 0.8), our sensitivity studies find the ratios relatively stable, even though the single-channel reflectances change in proportion to the surface albedo. The coefficients in Eq. (9) can be derived from either radiative transfer model simulations or real observational data from EPIC using multivariate least squares fitting. The advantage of the former is the exact knowledge of the model's atmosphere and clear or cloudy conditions. Conversely, its disadvantage is a limited number of atmospheric profiles and sometimes simplistic or even unrealistic cloud input to the model. The advantage of using observational data is the abundant radiance measurements that could be used as a training dataset, while the disadvantage is the limited knowledge of atmospheric profiles and uncertainties in clear-pixel identification. A common practice for developing a cloud mask algorithm is to use retrievals of simultaneous measurements from other better-equipped instruments or ground observations as the truth. Exact same-time overpass is quite rare even with the vast data volume from the polarorbiting satellites such as Terra and Aqua, and cloud detection over snow and ice from instruments such as MODIS is itself subject to large uncertainty. This could lead to some false cloud/clear identification in the training dataset and bias the results. Based on the above reasoning, we first derive the $\mathrm{O}_{2}$ band ratio thresholds with both model simulations and observations and then determine which set of coefficients is better suited for the EPIC cloud mask algorithm.

\section{Radiative transfer simulations}

\subsection{Model setup}

We used a radiative transfer simulator for EPIC (Gao et al., 2019) to generate the A-band and B-band reflectances over snow and ice surfaces. The EPIC simulator is built upon a radiative transfer model (Zhai et al., 2009, 2010) that solves multiple scattering of monochromatic light in the atmosphere and surface systems. Gas absorptions due to ozone, oxygen, water vapor, nitrogen dioxide, methane, and carbon dioxide are incorporated in all EPIC bands. The gas absorption cross sections are computed from the HITRAN line database (Rothman et al., 2013) using the Atmospheric Radiative Transfer Simulator (ARTS) (Buehler et al., 2011). Line broadening caused by pressure and line absorption parameters' dependences on temperature are considered. In the $\mathrm{O}_{2} \mathrm{~A}$ and $\mathrm{B}$ bands, radiances from line-by-line radiative transfer simulations are convolved with EPIC filter transmission functions. The model atmosphere assumes a one-layer cloud with a molecular layer both above and beneath. The $\mathrm{O}_{2}$ absorption within clouds is considered by assuming a fixed $\mathrm{O}_{2}$ molecule vertical profile (US standard or other specified atmospheres).

For clear-sky simulations, four atmospheric vertical profiles distributed with FASCODE (Chetwynd et al., 1994), originally from the Intercomparison of Radiation Codes in Climate Models (ICRCCM) project (Barker et al., 2003), are used: 1976 US standard atmosphere, midlatitude winter, subarctic summer, and subarctic winter atmospheres. Surface albedo values used in the simulations are $0.6,0.8$, and 1.0 to represent snow or ice surface. The snow albedo varies from 0.5 to 0.9 depending on snow age, grain size, purity, and Sun angle (Warren, 1982), while ice albedo varies between 0.5 and 0.7 . The daily mean snow albedo over Antarctica is generally over 0.8 (Pirazzini, 2004).

For cloudy-sky cases, simulations for both water and ice clouds are conducted since both phases are found over the polar regions (e.g., Cesana et al., 2012; Zhao and Wang, 2010). For water clouds, a gamma size distribution with effective radius of $10 \mu \mathrm{m}$ and an effective variance of 0.1 is assumed; for ice clouds, a fixed particle size $(30 \mu \mathrm{m})$ with a particle shape of the severely roughened aggregate of hexagonal columns is assumed (Yang et al., 2013). The cloud layer has varied optical thickness ranging from 0.2 to 30 and cloud top height (CTOP) from 1.0 to $15 \mathrm{~km}$ above the ground. The cloud geometrical thickness (CGT) varies from 0.5 to $4 \mathrm{~km}$.

The model simulates a variety of cases with 17 solar zenith angles (SZAs) ranging from 0 to $80^{\circ}, 18$ view zenith angles (VZAs) from 0 to $85^{\circ}$, and 37 relative azimuth angles (RAZMs) from 0 to $180^{\circ}$, all with an increment of $5^{\circ}$. In 
Table 1. Parameter setup in radiative transfer model simulations.

\begin{tabular}{lll}
\hline Clear-sky simulations & Atmospheric profiles & $\begin{array}{l}\text { Standard US 1976; midlatitude winter; subarctic } \\
\text { summer; subarctic winter }\end{array}$ \\
& $\begin{array}{l}\text { Solar zenith angles } \\
\text { View zenith angles }\end{array}$ & $\begin{array}{l}0-70^{\circ}, \text { every } 5^{\circ} \\
\text { Revery } 5^{\circ}\end{array}$ \\
& $\begin{array}{l}\text { Relative azimuth angles } \\
\text { Surface elevation }\end{array}$ & $0.0,2.5,5.0,7.5 \mathrm{~km}$ \\
& Surface albedo & $0.8,0.6,1.0$ \\
\hline Cloudy-sky simulations & Atmospheric profiles & Standard US 1976 \\
& Solar zenith angles & $0-80^{\circ}$, every $5^{\circ}\left(30,60^{\circ}\right.$ for surface elevation \\
& & $=2.5 \mathrm{~km}$ and surface albedo $=0.6)$ \\
& View zenith angles & $0-75^{\circ}$, every $5^{\circ}$ \\
& Relative azimuth angles & $0-180^{\circ}$, every $5^{\circ}$ \\
& Surface elevation & $0,2.5 \mathrm{~km}$ \\
& Cloud top height & $1.00,3.00,5.00,7.50,10.00,12.50,15.00 \mathrm{~km}$ \\
& Cloud geometric thickness & $0.50,1.00,2.00,4.00 \mathrm{~km}$ \\
& Cloud optical thickness & $0.22,0.82,1.72,3.06,5.05,8.03,12.46,19.09,28.96$ \\
& Surface albedo & $0.8,0.6$ \\
\hline
\end{tabular}

Table 2. Regression coefficients for Eq. (9) and multiple correlation coefficients (Rmulti) derived from model-simulated data and observations, respectively.

\begin{tabular}{lrrrrrrrrr}
\hline & \multicolumn{3}{c}{ A band } & & \multicolumn{4}{c}{ B band } & \\
\cline { 2 - 4 } \cline { 6 - 8 } & $c_{0}$ & $c_{1}$ & $c_{2}$ & Rmulti & $c_{0}$ & $c_{1}$ & $c_{2}$ & Rmulti \\
\hline Simulations & -0.3100 & -0.1341 & 0.5202 & 0.998 & -1.0201 & -0.1361 & 0.4888 & 0.999 \\
Observations & -0.1764 & -0.1152 & 0.4542 & 0.958 & -0.8672 & -0.1185 & 0.3995 & 0.934 \\
\hline
\end{tabular}

addition to the varying Sun-sensor geometry, the reflecting surface elevation is set from 0 to $7.5 \mathrm{~km}$ with a $2.5 \mathrm{~km}$ increment for the clear-sky sensitivity tests, while the cloudy-sky simulations are performed at sea level and $2.5 \mathrm{~km}$ above sea level. See Table 1 for a complete list of the model parameters.

\subsection{Clear-sky simulations}

We first examine whether the clear-sky radiative transfer simulations are consistent with the simplified relationship between the $\mathrm{O}_{2}$ band ratios and surface elevation and total air mass at typical surface albedo of 0.8 as discussed above (Eq. 9). A direct inspection of $\mathrm{O}_{2}$ band ratios at a fixed view zenith angle and relative azimuth angles with surface elevation indicates a nearly linear relationship between the two (Fig. 1a, b). The relationship depends on the solar zenith angle. At a higher solar zenith angle, not only are the ratios lower at all surface elevations but also the rate of change with height $\left(\frac{\partial r}{\partial Z}\right)$ is larger. However, the same relationship can be expressed as a quasi-linear relationship between $Z$ and the double logarithm of $\mathrm{O}_{2}$ band ratios at fixed zenith angles as indicated by Eq. (9) (Fig. 1c, d).

The variation of $\mathrm{O}_{2}$ band ratios with solar zenith angles has been discussed in previous works (Fischer and Grassl, 1991; Wang et al., 2008; Yang et al., 2013; Gao et al., 2019).
Here we show a more quantitative dependence of $\mathrm{O}_{2}$ band ratios as a function of the total relative air mass $(m)$ defined in Eq. (3) at fixed surface elevation (sea level in this case, Fig. 1e, f). The inverse relationship of $\mathrm{O}_{2}$ band ratios with $m$ is evident. Although EPIC is positioned close to the backscattering direction, there is a small difference in $\theta_{s}$ and $\theta_{v}$, generally smaller than $6^{\circ}$. The red dots show the simulations when the difference between $\theta_{s}$ and $\theta_{v}$ is smaller than $6^{\circ}$ to mimic the EPIC Sun-view geometry. The relationship derived from samples with restricted view zenith angles is not much different from that of all samples. Figure $1 \mathrm{~g}-\mathrm{h}$ further project this relationship as the logarithm of $m$ versus double logarithm of $\mathrm{O}_{2}$ band ratios as shown in Eq. (9). We notice that the linear relationship holds very well except for very large relative air mass $(\ln (m)>2.5$, which corresponds to zenith angles $>80^{\circ}$ ).

To account for both elevation and zenith angle effect, a multivariate least squares regression is applied in which $Z$ and $\ln (m)$ are taken as two independent terms and $\mathrm{d} b \ln \left(\frac{R_{\mathrm{abs}}}{R_{\text {ref }}}\right)$ is the dependent variable for the simulations, as suggested in Eq. (9), with the sample restricted to a zenith angle difference of below $6^{\circ}$. The results indicate high confidence of the fitting, with multicorrelation coefficients reaching 0.998 for both A-band and B-band simulations (Fig. 1i, j). The coefficients $c_{0}, c_{1}$, and $c_{2}$ are listed in Table 2. The 

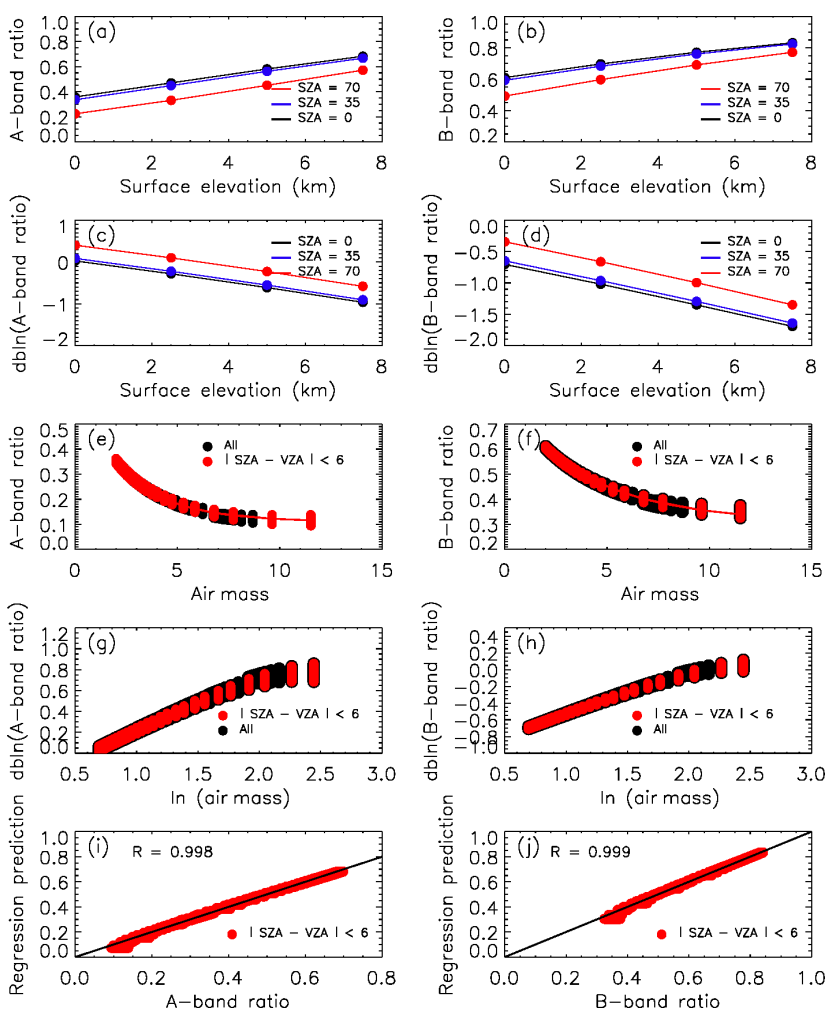

Figure 1. Relationships between model simulations of clear-sky Aband (left column) and B-band (right column) ratios with surface elevation and relative air mass. (a, b) $\mathrm{O}_{2}$ band ratios as a function of surface elevation; (c, d) double logarithm of $\mathrm{O}_{2}$ band ratios versus surface elevation; (e,f) $\mathrm{O}_{2}$ band ratios as a function of total relative air mass; (g, h) double logarithm of $\mathrm{O}_{2}$ band ratios versus logarithm of total relative air mass; (i, $\mathbf{j})$ scatter plot of fitted thresholds and $\mathrm{O}_{2}$ band ratios. The red points in panels $(\mathbf{e})-(\mathbf{j})$ show the simulations when the difference between $\theta_{s}$ and $\theta_{v}$ is smaller than $6^{\circ}$ to mimic the EPIC Sun-view geometry. The fitted thresholds are computed with a multivariable linear regression in which double logarithms of $\mathrm{O}_{2}$ band ratios are expressed as a function of surface elevation and logarithm of total relative air mass. The simulations use four atmospheric profiles: midlatitude winter, subarctic summer, subarctic winter, and standard US atmosphere. Surface albedo is set at 0.8 to represent snow and ice surface.

set of regression coefficients derived from simulations at surface albedo equal to 0.8 also predict very well the A-band ratios from simulations using different surface albedos $(0.6$ and 1.0) (Fig. 2a), with obvious divergence occurring only at large zenith angles $\left(>80^{\circ}\right)$ where no retrieval is performed for EPIC (Fig. 2b).

Table 2 also lists the set of coefficients derived from observations utilizing information from collocated GEO/LEO pixels. Details will be discussed in Sect. 4.
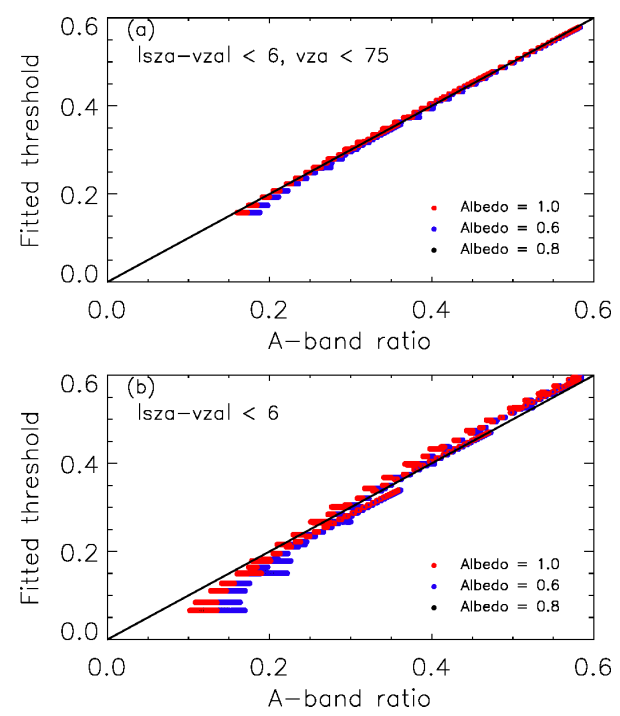

Figure 2. Scatter plot of model-simulated A-band ratios ( $y$ axis) at surface albedo $=0.6$ (blue), 0.8 (black), and 1.0 (red) versus computed with regression derived with the set of simulations at surface albedo $=0.8$ ( $x$ axis) for (a) view zenith angles $<75^{\circ}$ and (b) all view zenith angles. Absolute solar zenith angle and view zenith angle differences are smaller than $6^{\circ}$ for both plots. The results are from simulations using standard US atmosphere.

\subsection{Cloudy-sky simulations}

The coefficients in Table 2 can be applied to Eq. (9) to compute expected clear-sky band ratios. In order to test the feasibility of using the derived clear-sky band ratios as the thresholds for clear- and cloudy-pixel separation, we first evaluate the sensitivity of $\mathrm{O}_{2}$ band ratios to cloud properties. This is done by adding clouds with different optical thickness, cloud top height, and geometric thickness in the radiative transfer simulations and then comparing the $\mathrm{O}_{2}$ band ratios of cloudy sky with those of clear sky under the same Sun-view geometry. The results from solar and view zenith angles of 30 and $60^{\circ}$ and relative azimuth angle of $160^{\circ}$ are shown in Fig. 3, with the corresponding clear-sky values shown as the filled and open triangles, respectively. We notice that the $\mathrm{O}_{2}$ band ratios generally increase with the optical thickness and are higher for cloudy skies than for clear skies but with certain exceptions. At low zenith angles $\left(<30^{\circ}\right)$, we find very low sensitivity of $\mathrm{O}_{2}$ band ratios with cloud optical thickness when cloud top height is $1 \mathrm{~km}$ (Fig. 3a, b). Likewise, the sensitivity to cloud top height is very low at low optical thickness ( $\tau=1.7$ ) for the A band (Fig. 3c). For the B band, the $\mathrm{O}_{2}$ ratios decrease with cloud top height up to $5 \mathrm{~km}$ before increasing again at $\tau=1.7$ (Fig. 3d). Note that these figures show that adding a layer of optically thin cloud $($ COT $<3)$ actually decreases the ratio at $30^{\circ}$ zenith angle. The reason is that under this circumstance the reflectance of the reference channel increases more than the absorption channel, which indicates an increase in the photon path. The causes of the photon 

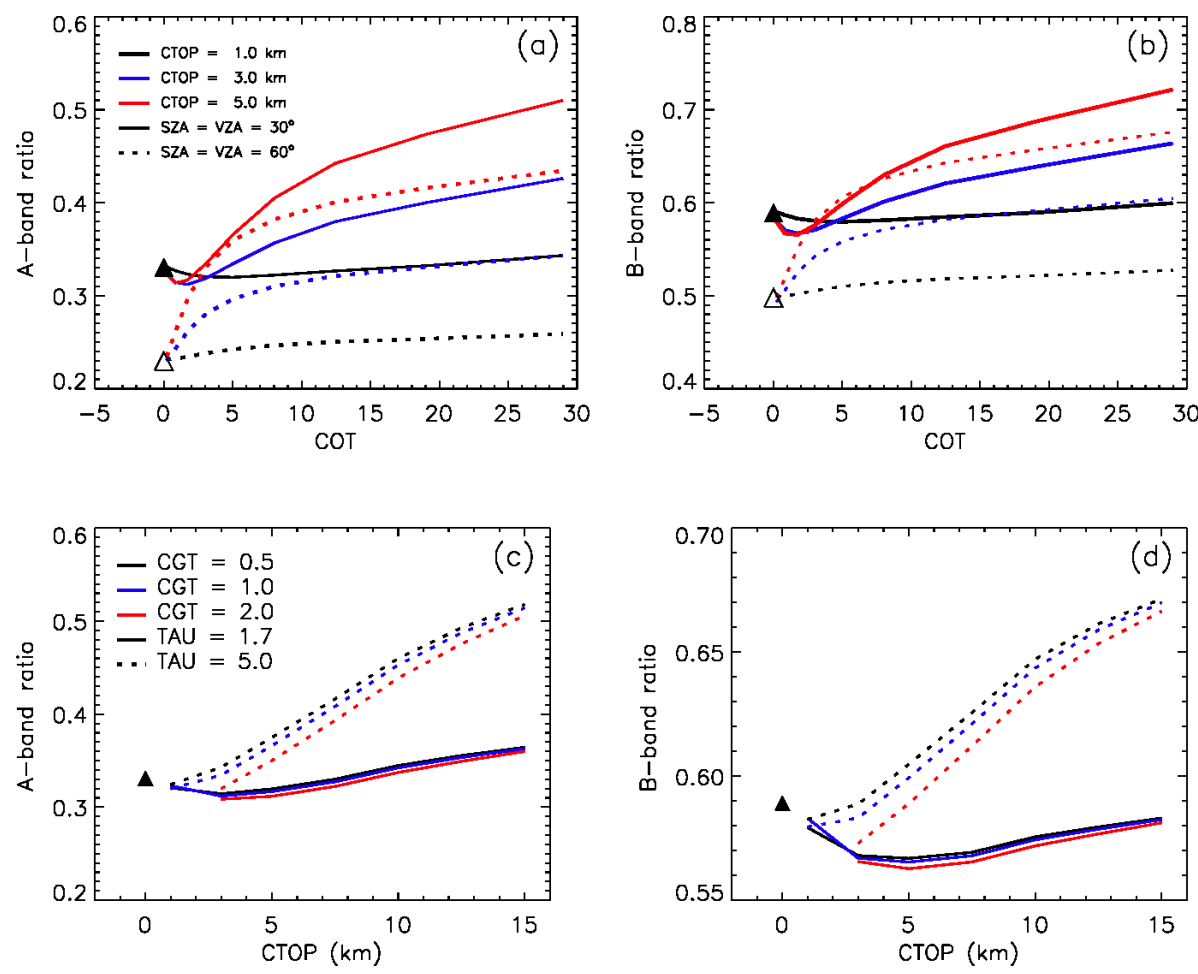

Figure 3. Model-simulated oxygen band ratios as a function of cloud optical thickness (COT) with cloud top height (CTOP) at $1.0 \mathrm{~km}$ (black), $3.0 \mathrm{~km}$ (blue) and $5.0 \mathrm{~km}$ (red) and solar zenith angles at $30^{\circ}$ (solid line) and $60^{\circ}$ (dotted lines), respectively for the (a) A band and (b) B band. Cloud geometric thickness is $1 \mathrm{~km}$. Oxygen band ratios at solar zenith angle $30^{\circ}$ as a function of CTOP with CGT of $0.5 \mathrm{~km}$ (black), $1.0 \mathrm{~km}$ (blue), and $2.0 \mathrm{~km}$ (red) as well as COT of 1.7 (solid) and 5.0 (dotted line) for the (c) A band and (d) B band, respectively. View zenith angle is the same as the solar zenith angle and relative azimuth angle is $160^{\circ}$ for all the simulations. The clear-sky simulations are marked with filled and unfilled triangles for solar and view zenith angles at 30 and $60^{\circ}$, respectively. Both clear-sky and cloudy-sky simulations use standard US atmosphere and zero ground elevation. Surface albedo is set at 0.8 to represent snow and ice surface.

path increase include multiple scattering inside the cloud and surface-cloud interaction. The strong surface-cloud interaction over the bright surface of snow and ice partly contributes to the low sensitivity of $\mathrm{O}_{2}$ band ratios for the low and thin clouds compared with relatively darker surfaces (further illustrated in Fig. 4). The sensitivity of $\mathrm{O}_{2}$ band ratios to cloud optical thickness and height increases with solar and view zenith angles, as can be seen from the SZA $=\mathrm{VZA}=60^{\circ}$ curves.

As the cloud mask only works when cloudy-sky $\mathrm{O}_{2}$ band ratios are greater than the clear-sky ratios, the difference between the two at low zenith angles $\left(\mathrm{VZA}=\mathrm{SZA}=30^{\circ}\right)$ is shown as a function of two major factors: COT and CTOP for the $\mathrm{A}$ band and $\mathrm{B}$ band at surface albedo equal to 0.8 , cloud geometric thickness of $1 \mathrm{~km}$, and sea level conditions (Fig. 4a, b), along with their sensitivities with altered geometric thickness (Fig. 4c, d), surface albedo (Fig. 4e, f), and surface elevation (Fig. 4g, h). If a difference larger than 0.01 is required to confidently detect cloud, the cases at the lower left side of each figure, which correspond to low COT and CTOP, will present difficulty in cloud detection. Smaller cloud geometric height (Fig. 4c, d) and sur- face albedo (Fig. 4e, f) tend to increase the sensitivity, while higher surface elevation (Fig. $4 \mathrm{~g}, \mathrm{~h}$ ) tends to decrease the sensitivity as compared to the cases in Fig. $4 \mathrm{a}$ and $\mathrm{b}$ for the A band and B band, respectively. These results show that the $\mathrm{O}_{2}$ band ratios can be used to detect clouds that are thick and/or high with much confidence over snow and ice surfaces. Difficulties still exist in detecting thin clouds or low clouds at low zenith angles $\left(<30^{\circ}\right)$. Note that the A band has better sensitivity than the B band, as expected. It should be pointed out that, for most of the cases, the solar zenith angles are larger than $30^{\circ}$ since snow and ice are present mainly in regions of high latitudes.

\section{EPIC cloud mask over snow and ice surfaces}

The regression results from Eq. (9) can be used as the thresholds for cloud detection. As discussed in Sect. 2, we can derive the thresholds using either radiative transfer simulations or satellite observations. The previous section discussed the path of using modeling results; here we attempt to derive the thresholds based on the real EPIC data. 

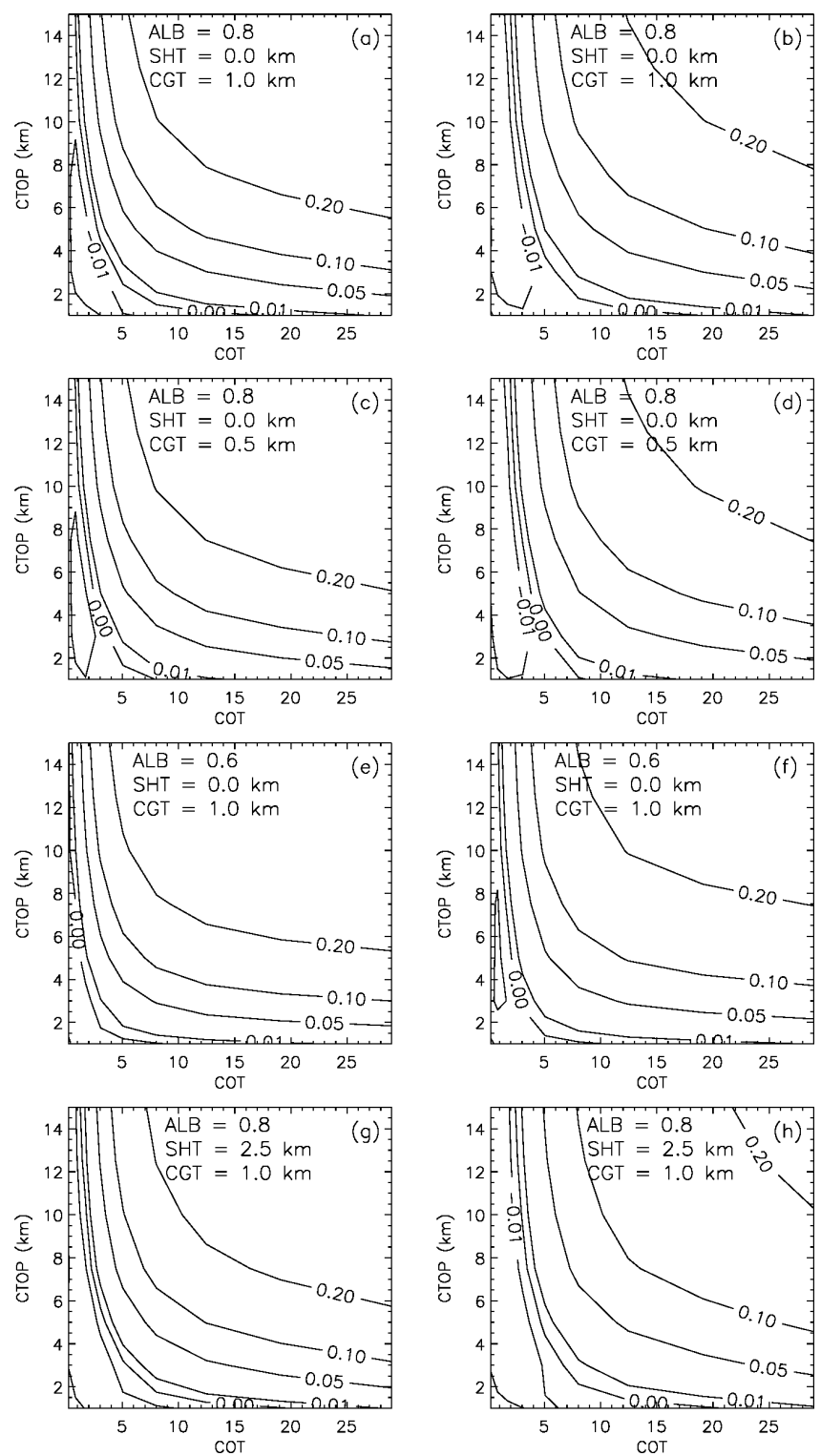

Figure 4. The difference of $\mathrm{O}_{2}$ band ratios (cloudy sky - clear sky) as a function of COT and CTOP at SZA $=\mathrm{VZA}=30^{\circ}$, $\mathrm{RAZM}=160^{\circ}$ at $(\mathbf{a}, \mathbf{b})$ surface albedo $(\mathrm{ALB})=0.8$, surface height $(\mathrm{SHT})=0 \mathrm{~km}$ (sea level), and cloud geometric thickness $(\mathrm{CGT})=$ $1 \mathrm{~km}$; the rest are the same as (a, b) but with the change of one parameter for $(\mathbf{c}, \mathbf{d}) \mathrm{CGT}=0.5 \mathrm{~km},(\mathbf{e}, \mathbf{f}) \mathrm{ALB}=0.6$, and $(\mathbf{g}$, h) $\mathrm{SHT}=2.5 \mathrm{~km}$. The right panels are for the A band and the left panels are for the $\mathrm{B}$ band.

For this purpose, the Langley GEO/LEO composite cloud product (Khlopenkov et al., 2017) and EPIC L1B data from January and July 2017 are used as the training dataset, and data from January and July 2016 are used for validation. The cloud retrievals in the composite data follows Minnis et al. (2011). Because of EPIC's large pixel size, one EPIC pixel corresponds to many GEO/LEO pixels each with its own cloud mask and optical properties retrievals; hence a com- posite pixel reports a cloud fraction based on cloud masks of the GEO/LEO pixels within it. It should be noted that cloud detections over snow and ice surfaces from instruments on GEO/LEO satellites are difficult as well. For example, the AVHRR-based cloud fraction was found to be basically unbiased over most of the globe except over the polar regions where a considerable underestimation of cloudiness could be seen during the polar winter when compared with cloud information from the Cloud-Aerosol Lidar with Orthogonal Polarization (CALIOP) on board the CALIPSO satellite. The overall probability of detecting clouds in the polar winter could be as low as $50 \%$ over the highest and coldest parts of Greenland and Antarctica, with a large fraction of optically thick clouds remaining undetected (Karlsson et al., 2018). Wang et al. (2016) shows MODIS from Terra and Aqua misidentifies cloud as clear as high as $20 \%$ over snow-covered or sea ice regions in Antarctica. They show that misidentification of clear as cloud also occurs quite frequently in eastern Antarctica during boreal spring and fall. Over snow-covered high mountains over the Tibetan Plateau, a recent study by Shang et al. (2018) found the cloud detection rate to be $73.55 \%$ and $80.15 \%$ for the Advanced Himawari Imager (AHI) and MODIS, respectively. All these studies use the CALIOP cloud detection as ground truth and highlight the large uncertainties in cloud detection from passive radiometers over snow and ice surfaces and over high mountain areas.

Keeping these in mind, we use the GEO/LEO composite cloud product as the training and validation dataset because of its pole-to-pole coverage and availability. The cloud fraction and surface scene types from the composite dataset are used to select the clear pixels (100\% clear) over snow and ice surfaces (when $90 \%$ of the scene type is permanent snow or ice, seasonal snow, or ice over water). Surface type is reported in the Langley GEO/LEO dataset, which is based on the IGBP surface type dataset and the Near-real-time Ice and Snow Extent (NISE) dataset from the National Snow and Ice Data Center (NSIDC) (Brodzik and Stewart, 2016). To reduce the uncertainties, we further restrict the difference between the GEO/LEO and the EPIC to be within $5 \mathrm{~min}$. We also restrict the analysis on pixels with view zenith angle less than $80^{\circ}$. The surface elevation data are from the National Geophysical Data Center (NGDC) TerrainBase global digital terrain model (DTM), version 1.0 (Row and Hastings, 1994).

The same type of multivariate least squares regression is performed for the clear-sky pixels using the elevation and logarithm of total relative air mass as independent variables and the double logarithm of the $\mathrm{O}_{2}$ band ratios as the dependent variables as suggested by Eq. (9). The derived regression coefficients (Table 2) are quite close to those derived from the model simulations with slightly larger scatter (Fig. 5a, b). One major source of uncertainty may come from the GEO/LEO cloud identification. As mentioned above, cloud detection over snow and ice surfaces is very challenging even 

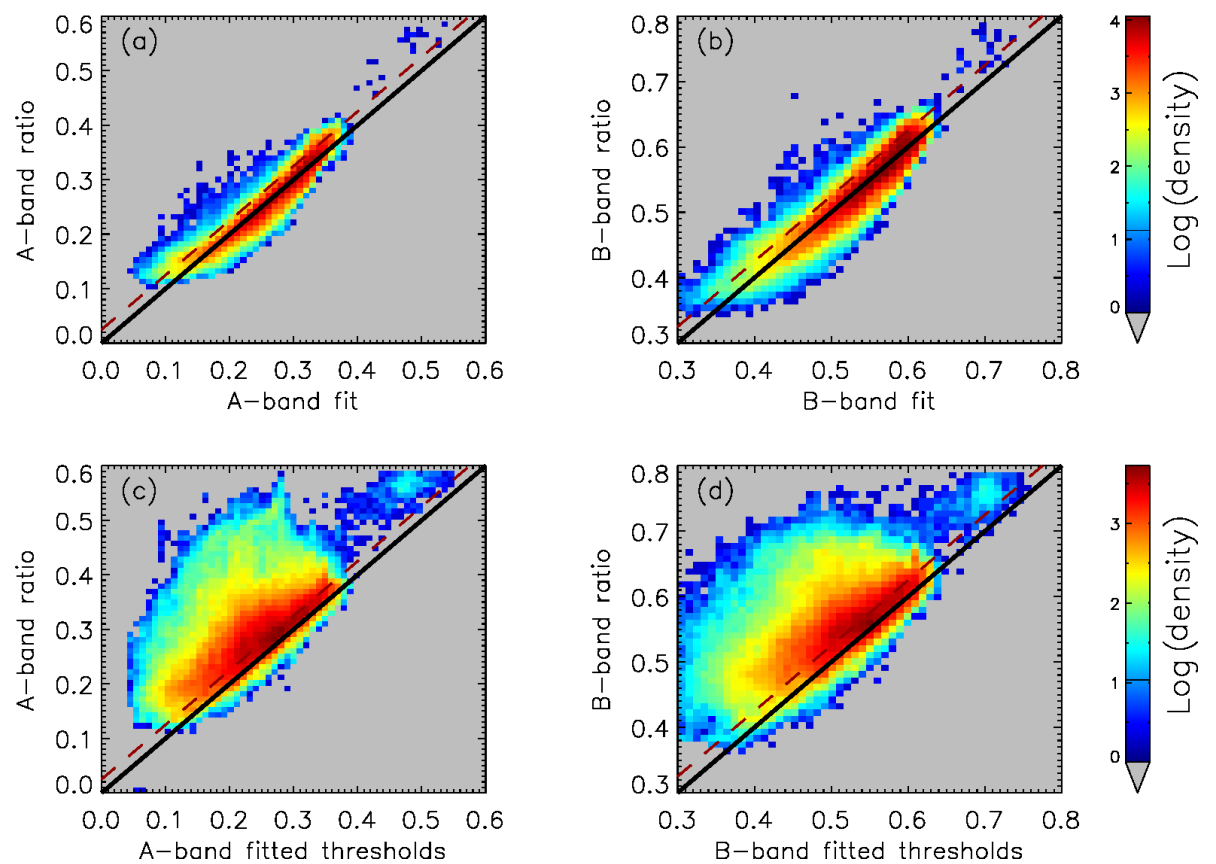

Figure 5. Scatter plot of regression fit versus A-band (a, c) and B-band (b, d) ratios for clear-sky (a, b) and cloudy-sky (c, d) pixels from EPIC measurements over global snow and ice surfaces in January and July 2017. The regression is derived with clear-sky oxygen band ratio as a function of surface elevation and air mass. The pixels on the left $(\mathbf{b}, \mathbf{d})$ side of black lines could be identified as cloudy (clear) as the observed ratio is larger (smaller) than the predicted threshold. The dashed lines (increase the predicted ratios by 0.025 ) provide better division of clear and cloudy pixels.

Table 3. The logic table for combining the cloud mask results from the A- and B-band tests. Acronyms: CldHC, cloud with high confidence; CldLC, cloud with low confidence; ClrHC, clear with high confidence; ClrLC, clear with low confidence.

\begin{tabular}{llllll}
\hline & & \multicolumn{4}{c}{ A-band test } \\
\cline { 3 - 6 } & & CldHC & CldLC & ClrLC & ClrHC \\
\hline B-band test & CldHC & CldHC & CldLC & CldLC & CldLC \\
& CldLC & CldLC & CldLC & CldLC & ClrLC \\
& ClrLC & CldLC & CldLC & ClrLC & ClrLC \\
& ClrHC & CldLC & ClrLC & ClrLC & ClrHC \\
\hline
\end{tabular}

for GEO/LEO satellites with more spectral channels. Cloud contaminated pixels might have lower or higher $\mathrm{O}_{2}$ band ratios than the clear-sky values depending on the optical thickness of the cloud and the Sun-view geometry (Fig. 3). Other sources of uncertainties, such as geolocation, surface elevation, and atmospheric profile, can also contribute to the larger scatter in the observational data.

Obviously, the clear-sky thresholds predicted from observational data must be adjusted to provide a better overall performance since the regression model is designed to predict the mean rather than the upper bound of clear-sky band ratios. The same regression coefficients applied to cloudysky samples indicate many overlapping of $\mathrm{O}_{2}$ band ratios from clear-sky and cloudy-sky pixels (Fig. 5c, d). A threshold value that is too high will guarantee the clear-sky identification but underestimate cloudy pixels, and a value that is too low will lead to overestimation of cloudy pixels. To achieve the best overall clear-sky and cloudy-sky performance, i.e., a balanced correct detection rate and false detection rate as discussed in Sect. 5, we set the threshold value by increasing the ratios derived from Eq. (10) by 0.025 so that the cloud mask threshold is close to the upper quantile of the clear-sky values (dashed red line in Fig. $5 \mathrm{c}$ and d).

Results show that using the set of coefficients derived from the model simulations captures most of the clear-sky samples without being adjusted (figures not shown). We found that, even though the thresholds derived from the observational data perform slightly better when applied back to the same training dataset, they underperform the model-derived algorithm when applied to a different data period (January and July 2016). One likely reason is that the cloud identification in the observational training dataset has its own nonnegligible uncertainties. These uncertainties will not affect the performance in the training dataset but affect the algorithm performance in a different data period. For this purpose, we adopt the algorithm derived from the model simulations for the rest of this paper.

Following the current EPIC cloud mask algorithm, we also set an upper and a lower threshold that is 0.02 above or below the model-predicted threshold $\left(\mathrm{RT}_{0}\right)$. A cloud mask $(\mathrm{CM})$ 
(a)

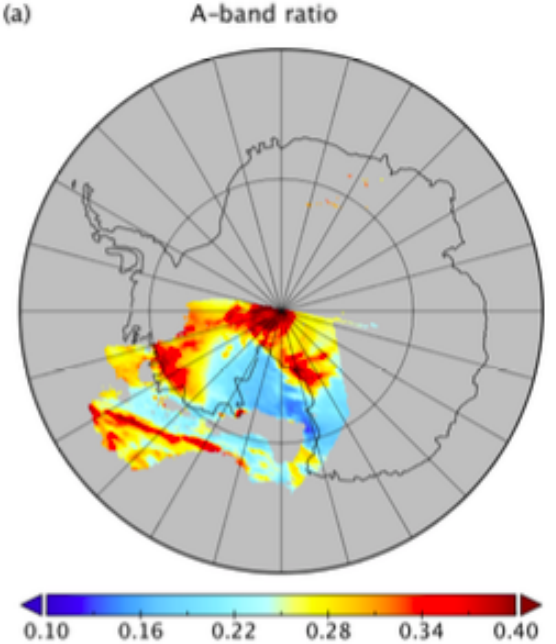

(c)

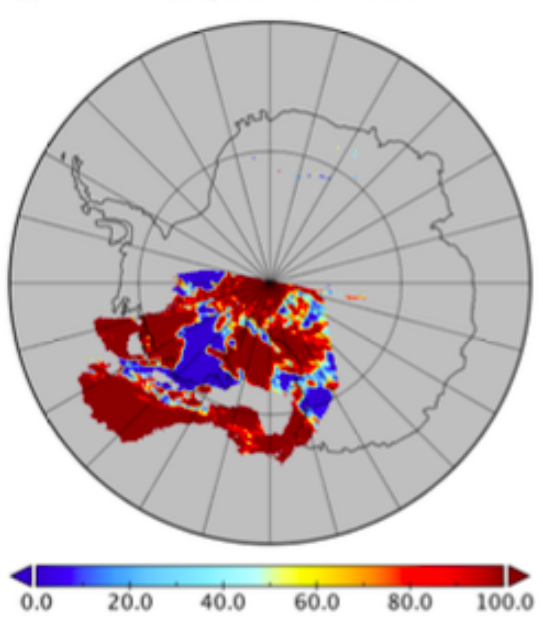

(b)

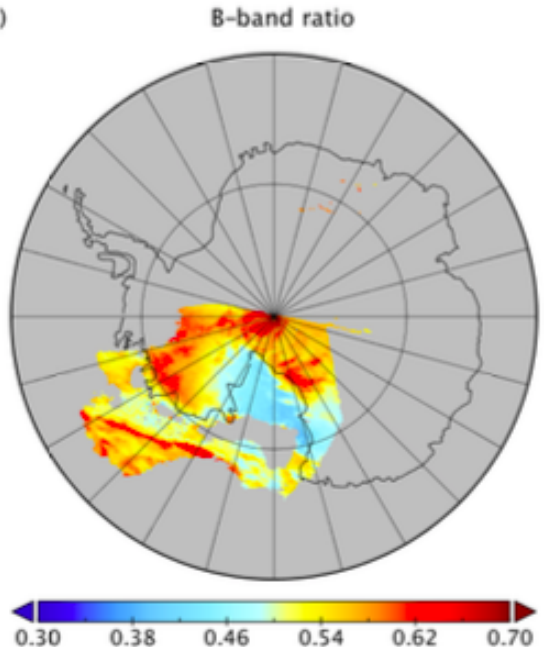

(d)

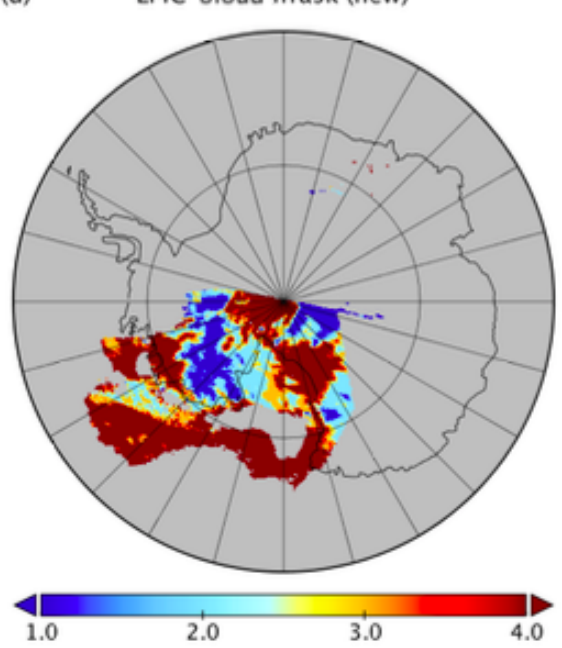

Figure 6. Section of an EPIC granule on 23 December 2017, 17:07 UTC time, with matching GEO/LEO overpass within 5 min of the EPIC scan over western Antarctica. (a) A-band ratio, (b) B-band ratio, (c) cloud fraction from the GEO/LEO composite, and (d) cloud mask from the new algorithm.

confidence level is determined for each pair of the $\mathrm{O}_{2}$ band ratios based on whether the ratios fall between these intervals/thresholds:

$\mathrm{CM}=\left\{\begin{array}{ccc}4 & \text { Ratio }>\mathrm{RT}_{0}+0.02 ; & \text { CldHC } \\ 3 \mathrm{RT}_{0}<\text { Ratio }<\mathrm{RT}_{0}+0.02 ; & \text { CldLC } \\ 2 \mathrm{RT}_{0}-0.02<\mathrm{Ratio}_{2}<\mathrm{RT}_{0} ; & \text { ClrLC } \\ 1 & \text { Ratio }<\mathrm{RT}_{0}-0.02 ; & \text { ClrHC }\end{array}\right\}$.

Here, CldHC, CldLC, ClrHC, and ClrLC refer to cloud with high confidence, cloud with low confidence, clear with high confidence, and clear with low confidence, respectively. The final confidence level is determined by combing the two results from the A- and B-band tests according to Table 3. Note that we only define high confidence cloud (CldHC) or high confidence clear (ClrHC) when both tests show cloud or clear with high confidence.
An illustration of EPIC $\mathrm{O}_{2}$ band ratios and the derived cloud mask over the Antarctic on 23 December 2017 is shown in Fig. 6, along with cloud fraction derived from the GEO/LEO composite. In this figure, the A-band and B-band ratios show not only the presence of clouds but also the effect of elevation, as the low values over the Ross Ice Shelf are clearly influenced by the low elevation in that area. The new cloud mask detects the majority of the cloud area, but some portion of clouds over this region is missing. This could be because the clouds in this scene over the Ross Ice Shelf are low.

\section{Algorithm validation}

Using the thresholds from radiative transfer simulations, we reprocessed the EPIC cloud mask over snow and ice surfaces 

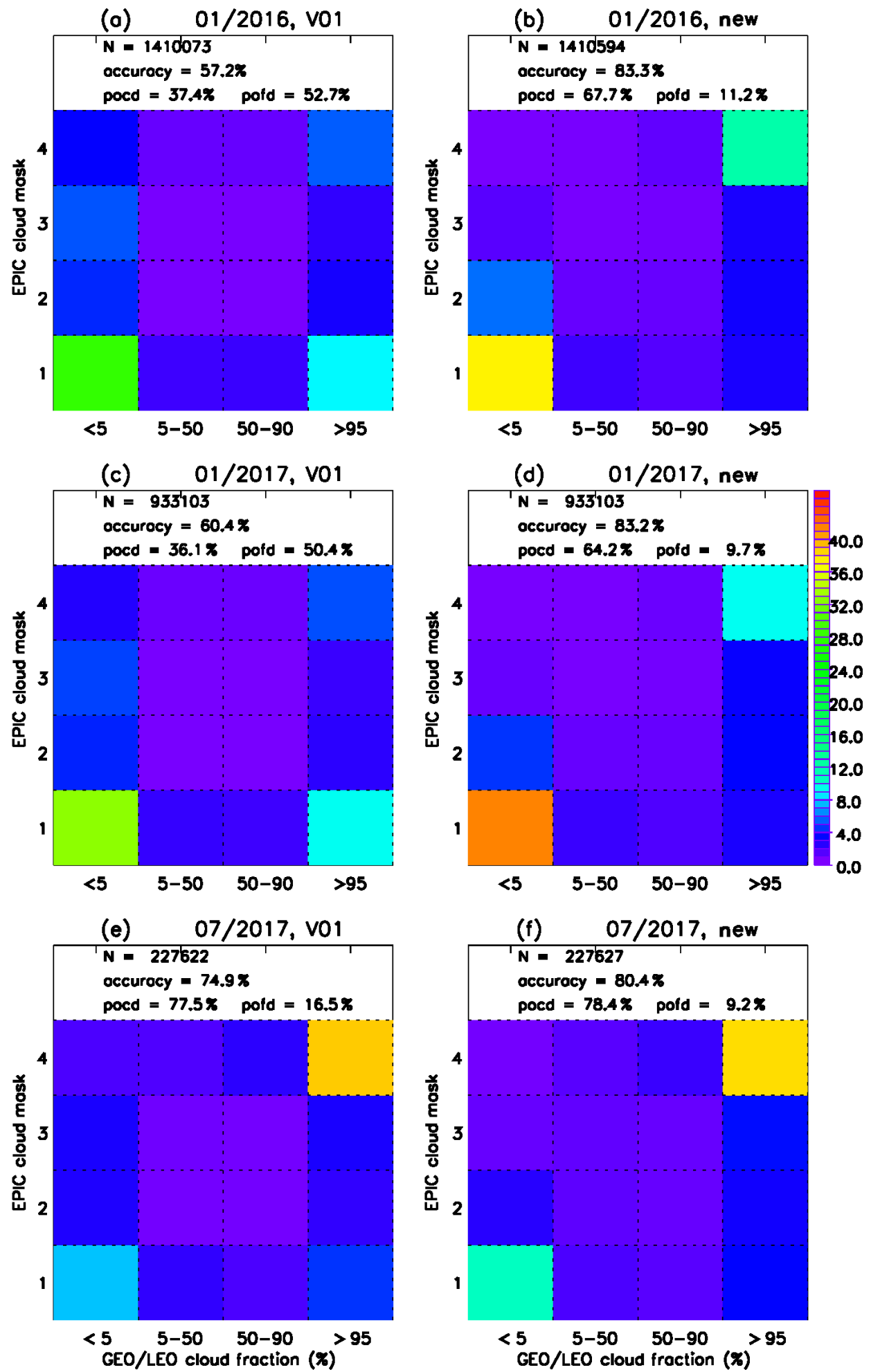

Figure 7. Percentage of pixels in each pixel-by-pixel matchup category between cloud mask from EPIC and GEO/LEO composite cloud fraction over snow and ice surfaces for January 2016 (a, b), January 2017 (c, d), and July 2017 (e, f). Panels (a, c, e) are from the current EPIC cloud mask algorithm, and panels $(\mathbf{b}, \mathbf{d}, \mathbf{f})$ are from the new algorithm. The diagonal squares represent agreement between the GEO/LEO and EPIC cloud mask, while the off-diagonal squares represent disagreement between the two products. The number of samples, accuracy, probability of correct detection (POCD), and probability of false detection (POFD) are shown in the white area on top of each figure. 
(a) GEO/LEO

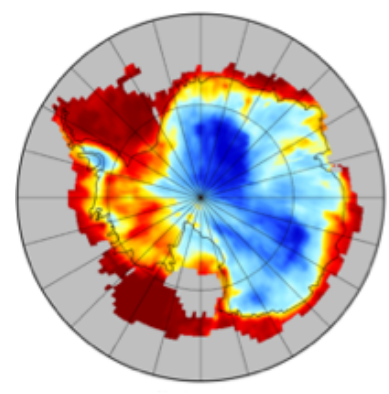

(b) EPIC (v01)

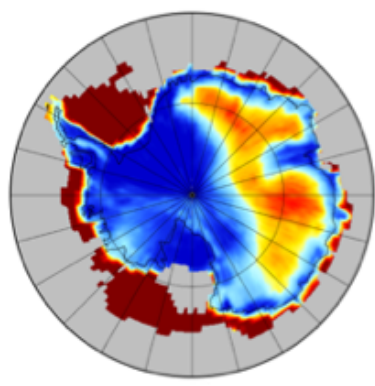

(c) EPIC (new)

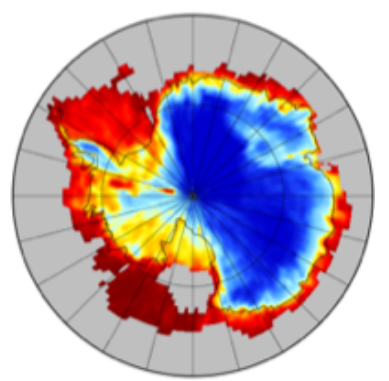

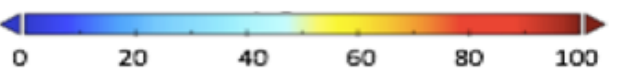

Figure 8. Cloud fractions derived from (a) composite GEO/LEO retrievals, (b) original EPIC cloud mask, and (c) new EPIC cloud mask over Antarctica in January 2017.

(a)

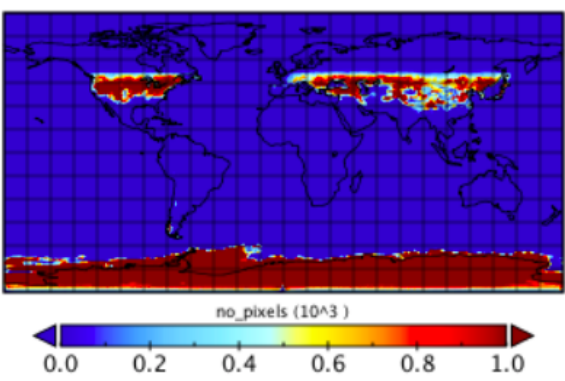

(c)

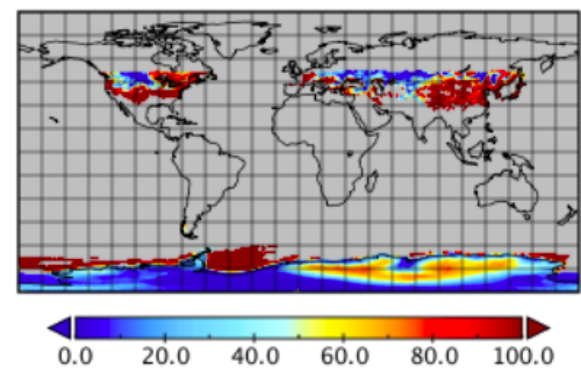

(b) GEO/LEO cloud fraction

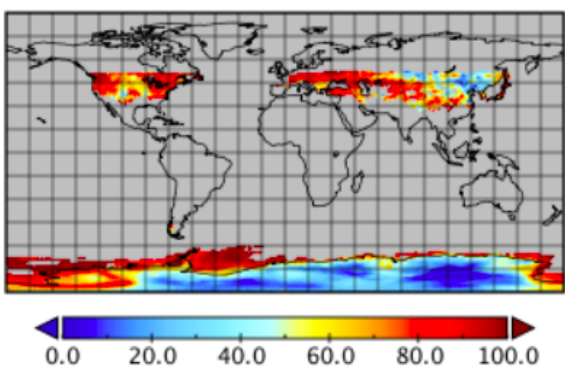

(d)

EPIC cloud fraction (new)

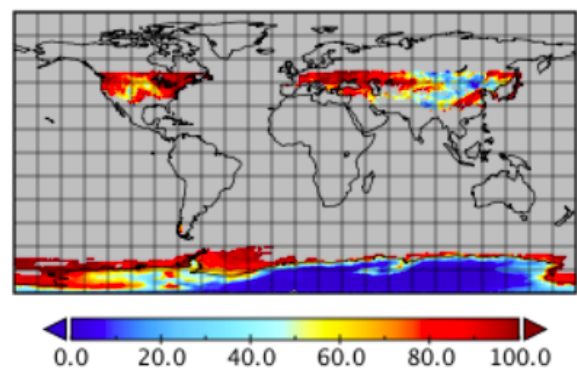

Figure 9. (a) Number of ice/snow pixels and monthly mean cloud fractions derived from the (b) GEO/LEO composites, (c) original EPIC cloud mask algorithm, and (d) new algorithm in $1^{\circ} \times 1^{\circ}$ grids for January 2016.

for all the collocated pixels in three months: January 2016, January 2017, and July 2017.

We divide the GEO/LEO cloud fraction into four categories to match with the CM in EPIC:

GEO/LEO CM $=\left\{\begin{array}{cc}4: & \text { cloud fraction } \geq 95 \% \\ 3: 50 \% & \leq \text { cloud fraction }<95 \% \\ 2: 5 \% & \leq \text { cloud fraction }<50 \% \\ 1: & \text { cloud fraction }<5 \%\end{array}\right\}$.

Figure 7 shows the $4 \times 4$ fusion matrixes of the EPIC cloud mask with the GEO/LEO cloud fraction for the three months. The diagonal squares represent agreement between the GEO/LEO and EPIC cloud masks, while the off-diagonal squares represent disagreement between the two products. For January 2016 and 2017, we notice that the original algorithm has a high percentage of pixels in the bottom-left corner (clear-clear) category, but there is a large percentage of GEO/LEO cloudy pixels in the $>95 \%$ category missidentified by EPIC as clear (cloud mask $=1$ ). There are also a considerable amount of pixels in the low GEO/LEO cloud fraction category $(<5 \%)$ being classified as cloudy $(\mathrm{CM}=$ $3,4)$. Improvement is evident for the new algorithm, where percentages of pixels in clear-clear $(<5 \%$ and $\mathrm{CM}=1)$ and cloudy-cloudy ( $>95 \%$ and $\mathrm{CM}=4)$ are significantly in- 
creased. The changes in July 2017 are less obvious, as the original algorithm already captures large percentage of pixels in clear-clear and cloudy-cloudy categories.

To quantitatively measure the performance of the cloud masking algorithms, we further define a binary partition of negative $(\mathrm{CM}=1,2$, or cloud fraction $<5 \%$ and $5 \%-$ $50 \%)$ and positive $(\mathrm{CM}=3,4$, or cloud fraction $50 \%-$ $95 \%$ and $>95 \%$ ) cloud identification for both EPIC and GEO/LEO, which results in four total combinations. Successful retrievals consist of TP (true positive) and TN (true negative) cases, in which both algorithms identify the pixel as cloudy and clear, respectively, and unsuccessful retrievals consist of FN (false negative) and FP (false positive) - where EPIC identifies a pixel as clear and cloudy, respectively, opposite to the GEO/LEO cloud mask. Assuming GEO/LEO's retrievals are the "truth", a number of parameters as a measure of EPIC's CM accuracy are computed:

$$
\begin{aligned}
& \text { Accuracy }=\frac{\mathrm{TP}+\mathrm{TN}}{\mathrm{TP}+\mathrm{TN}+\mathrm{FN}+\mathrm{FP}}, \\
& \mathrm{POCD}=\frac{\mathrm{TP}}{\mathrm{TP}+\mathrm{FN}}, \\
& \mathrm{POFD}=\frac{\mathrm{FP}}{\mathrm{TN}+\mathrm{FP}} .
\end{aligned}
$$

Here POCD and POFD are the probability of correct detection and probability of false detection, respectively. For January 2016 and 2017, compared to the current product, the accuracies have been improved considerably from $57 \%-60 \%$ to around $83 \%$. The POCD is nearly doubled (from $36 \%$ to $64 \%-67 \%$ ) with a significant reduction of POFD (a drop from around $50 \%$ to $10 \%$ ). The original algorithm performs relatively well in July 2017, with a probability of correct detection (POCD) of $77.5 \%$ and a low probability of false detection (POFD) of $16.5 \%$; hence the improvement for this month is relatively small.

Figure 8 shows the cloud fraction on a $1^{\circ} \times 1^{\circ}$ grid for January 2017 over snow- and ice-covered Antarctica. Note that here we lift the $5 \mathrm{~min}$ time difference limitation and use all available pixels with view zenith angles less than $75^{\circ}$ from the GEO/LEO composites (Khlopenkov et al., 2017) in order to have a full coverage of the region. The cloud fraction map from GEO/LEO shows a belt of high cloud fraction originated from the midlatitude storm track reaching the edge of the continent. Onto the icy plateau of East Antarctica, cloud fraction quickly decreases. High cloud fraction is found over West Antarctica. The cloud fraction from the original algorithm shows quite an opposite cloud distribution pattern between West and East Antarctica. This is likely due to the fixed threshold that is too low for the high elevation in East Antarctica and too high for the low elevation in West Antarctica. By taking the elevation into account, the new algorithm identifies the regional cloud distribution much better. In addition, the new algorithm also has a better cloud fraction match around the edge of the Antarctic continent.
To examine the performance of the new algorithm on the global scale, we plotted the gridded cloud fraction over snow and ice surfaces for the entire globe in January 2016 (Fig. 9). The number of snow/ice pixels used for the map is also shown, because sample numbers affect the quality of the monthly mean. We notice that the number of snow/ice pixels per grid is much higher in January over Antarctica. There are also considerable amounts of snow/ice pixels in Northern Hemisphere high-latitude regions and the southern tip of the Andes. There is no retrieval north of $50^{\circ} \mathrm{N}$ due to no daylight or view zenith angle too large in January (DSCOVR only has observations for the daytime Earth). Comparisons show that the new algorithm improves cloud distributions noticeably.

Figure 10 shows a similar map but for July 2017. During the boreal summer, the cloud mask algorithm has retrievals over the entire Northern Hemisphere but not for the part of Antarctica south of $65^{\circ} \mathrm{S}$ due to the polar night. The GEO/LEO cloud fraction map indicates cloud fraction $>80 \%$ over snow and ice surfaces over most of the regions in July except over Greenland. The original algorithm has similar cloud fraction in most areas over snow and ice surfaces, except over southeast Greenland, where it has significantly more cloud than the other parts of Greenland. This is likely due to the original algorithm's failure to take into consideration the high elevation there. On the other hand, the underestimation of cloud fraction at the southern tip of the Andes could be due to its failure to take into account the large solar and view zenith angles in summer. The new algorithm detects a significantly lower amount of cloud fraction in Greenland and improves the cloud detection in the aforementioned high mountain areas.

Even though the new cloud mask has improved the accuracy and general distribution compared with the GEO/LEO retrievals, regional differences between the two can still be quite large. This is partly due to the large uncertainty of cloud detection from GEO/LEO over snow/ice itself and partly due to the intrinsic difficulty of using $\mathrm{O}_{2}$ band ratios in detecting the low cloud and thin cloud as discussed before. In addition, the time difference between EPIC and GEO/LEO observations can also impact the comparison between the two. Stratifying the performance based on difference in the observation time, we find a larger difference in the observing time leads to slightly lower POCD, higher POFD, and an overall decreasing accuracy (Fig. 11).

\section{Summary and discussion}

Due to limited spectral channels, especially the lack of infrared and near-infrared channels in the DSCOVR EPIC instrument, cloud detection for EPIC over snow and ice poses a great challenge. The existing EPIC cloud mask algorithm employs two oxygen pair ratios in the A band $(764,780 \mathrm{~nm})$ and $\mathrm{B}$ band $(688,680 \mathrm{~nm})$ for cloud detection over the snow and ice surfaces. This method is based on the mechanism that 
(a)

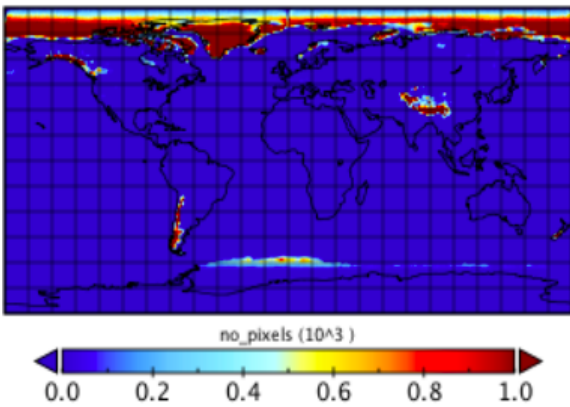

(c)

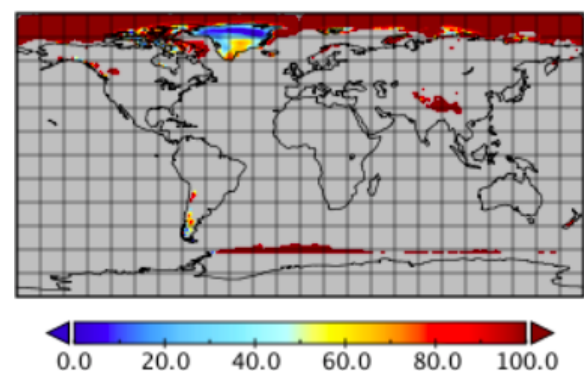

(b) GEO/LEO cloud fraction

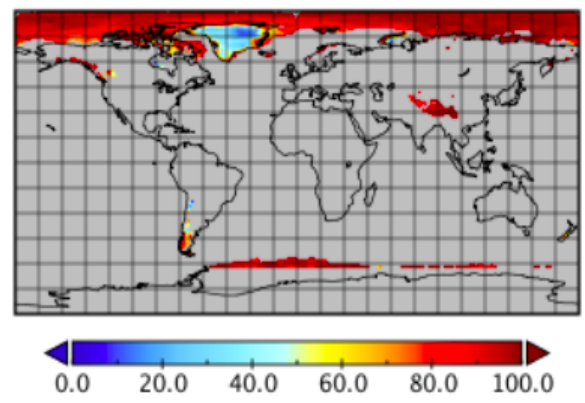

(d)

EPIC cloud fraction (new)

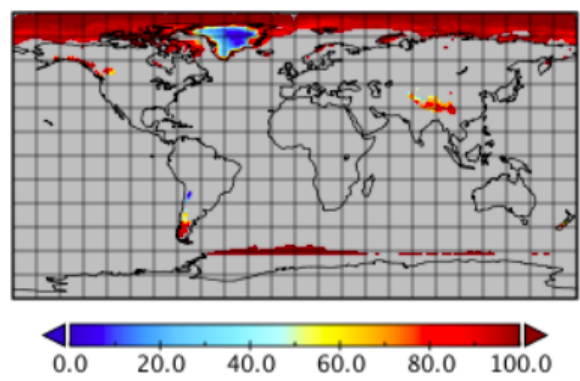

Figure 10. (a) Number of ice/snow pixels and monthly mean cloud fractions derived from (b) GEO/LEO composites, (c) original EPIC cloud mask algorithm, and (d) new algorithm in $1^{\circ} \times 1^{\circ}$ grids for July 2017.

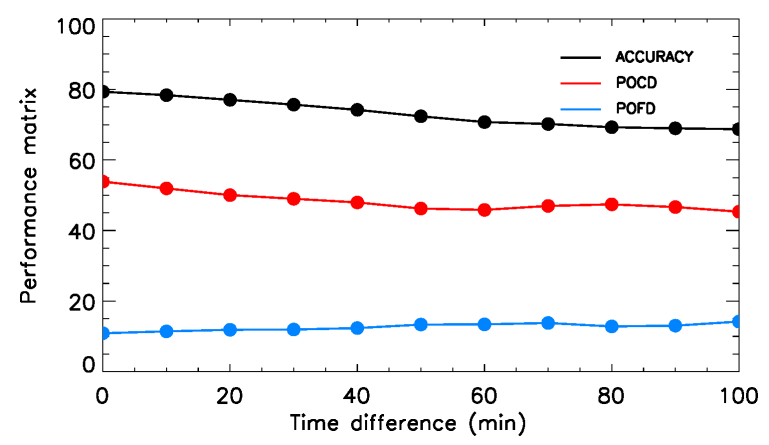

Figure 11. Performance metrics for January 2017 as a function of time difference between EPIC and GEO/LEO instrument measurements. POCD: probability of correct detection; POFD: probability of false detection.

photons reflected by clouds above the surface will travel, on average, a shorter distance through the atmosphere and so experience less absorption by $\mathrm{O}_{2}$; hence a threshold can be set to separate cloudy pixels from clear pixels. However, clearsky $\mathrm{O}_{2}$ band ratios depend on a number of factors such as surface elevation and Sun-view geometry that impact the total absorption air mass; these factors need to be accounted for.

In this study, we use both the radiative transfer theory and model simulations to quantify the relationship between the $\mathrm{O}_{2}$ band ratios with surface elevation and zenith angles.
Thresholds are derived as a function of surface elevation and Sun-view geometry based on both model simulation results and observations. The model-derived algorithm is chosen because it performs better when applied to the observations that were not used in the training dataset. The new algorithm increases the accuracy of the EPIC cloud mask over snow and ice surfaces in winter by more than $20 \%$. This is achieved through a significant reduction of the false detection rate from $50 \%$ to $10 \%$ and through nearly doubling the correct detection rate (from $36 \%$ to $64 \%-67 \%$ ). The improvement in July is mild, with the main improvement observed over Greenland. Of course, these performance metrics are based on comparison with GEO/LEO cloud mask, which has quite a large uncertainty over snow and ice surfaces itself. In addition to significant improvement in cloud detection over Antarctica, the new algorithm also improves cloud detection over Greenland and some midlatitude high mountain areas.

Limitations of this method include difficulties in identifying thin clouds with optical thickness less than 3 or low cloud below $3 \mathrm{~km}$ due to the lack of sensitivity in $\mathrm{O}_{2}$ band ratios under these circumstances. Compared with the infrared-based techniques, one advantage of this oxygen band technique is that it is relatively insensitive to the surface and atmosphere temperature. Therefore, the method presented in this work provides a solution to polar cloud detection when infrared channels are not available or struggle to distinguish between cloudy and clear scenes. We anticipate that cloud detection 
using the oxygen band technique will be of great value in future missions.

Data availability. The DSCOVR level-1 and level2 data used in this paper are publicly available from the NASA Langley Atmospheric Sciences Data Center (ASDC) (https://doi.org/10.5067/EPIC/DSCOVR/L1B.002, Geogdzhayev and Marshak, 2018, https://doi.org/10.5067/EPIC/DSCOVR/L2_Cloud_01, Yang et al., 2019). The ice cloud optical properties database was obtained from Ping Yang at the Texas A\&M University.

Author contributions. All authors contributed to the design of radiative transfer model simulations and the writing of the paper. YZ developed the new improvements of the cloud mask algorithm over ice and snow surfaces, conducted the data analysis, and drafted the paper. YY led the development of the entire EPIC cloud algorithm and provided the original EPIC cloud mask code and guidance throughout this work. MG conducted the initial model simulations and PZ completed full sets of model simulations used in the study.

Competing interests. The authors declare that they have no conflict of interest.

Acknowledgements. We thank Piet Stammes and two anonymous reviewers for their thorough and very helpful comments. This research was supported by the NASA DSCOVR Earth Science Algorithms program managed by Richard Eckman. We also thank Professor Ping Yang from the Texas A\&M University for providing the ice cloud optical properties database.

Financial support. This research has been supported by NASA (DSCOVR science algorithm).

Review statement. This paper was edited by Piet Stammes and reviewed by two anonymous referees.

\section{References}

Ackerman, S., Strabala, K., Menzel, P., Frey, R., Moeller, C., and Gumley, L.: Discriminating clear-sky from cloud with MODIS algorithm theoretical basis document (MOD35), MODIS Cloud Mask Team, Cooperative Institute for Meteorological Satellite Studies, University of Wisconsin, 2010.

Barker, H. W., Stephens, G. L., Partain, P. T., Bergman, J. W., Bonnel, B., Campana, K., Clothiaux, E. E., Clough, S., Cusak, S., Delamere, J., Edwards, J., Evans, K. F., Fouquart, Y., Freidenreich, S., Galin, V., Hou, Y., Kato, S., Li, J., Mlawer, E., Morcrette, J.-J., O'Hirok, W., Raisanen, P., Ramaswamy, V., Ritter, B., Rozanov, E., Schlesinger, M., Shibata, K., Sporyshev, P., Sun, Z., Wendisch, M., Wood, N., and Yang, F.: Assessing 1D atmo- spheric solar radiative transfer models: Interpretation and handling of unresolved clouds, J. Climate, 16, 2676-2699, 2003

Brodzik, M. J. and Stewart, J. S.: Near-Real-Time SSM/I-SSMIS EASE-Grid Daily Global Ice Concentration and Snow Extent, Version 5. [Indicate subset used], Boulder, Colorado USA, NASA National Snow and Ice Data Center Distributed Active Archive Center, https://doi.org/10.5067/3KB2JPLFPK3R, 2016.

Buehler, S. A., Eriksson, P., and Lemke, O.: Absorption lookup tables in the radiative transfer model ARTS, J. Quant. Spectrosc. Ra., 112, 1559-1567, https://doi.org/10.1016/j.jqsrt.2011.03.008, 2011.

Cesana, G., Kay, J. E., Chepfer, H., English, J. M., and de Boer, G.: Ubiquitous low-level liquid-containing Arctic clouds: New observations and climate model constraints from CALIPSO-GOCCP, Geophys. Res. Lett., 39, L20804, https://doi.org/10.1029/2012GL053385, 2012.

Chetwynd H. J., Wang, J., and Anderson, G. P.: Fast Atmospheric Signature CODE (FASCODE): an update and applications in atmospheric remote sensing, Proc. SPIE 2266, Optical Spectroscopic Techniques and Instrumentation for Atmospheric and Space Research, https://doi.org/10.1117/12.187599, 1994.

Ding, S., Wang, J., and Xu, X.: Polarimetric remote sensing in oxygen A and B bands: sensitivity study and information content analysis for vertical profile of aerosols, Atmos. Meas. Tech., 9, 2077-2092, https://doi.org/10.5194/amt-9-2077-2016, 2016.

Ferlay, N., Thieuleux, F., Cornet, C., and Davis, A. B.: Toward New Inferences about Cloud Structures from Multidirectional Measurements in the Oxygen A Band: Middleof-Cloud Pressure and Cloud Geometrical Thickness from POLDER-3/PARASOL, J. Appl. Meteorol. Clim., 49, 2492 2507, https://doi.org/10.1175/2010JAMC2550.1, 2010.

Fischer, J. and Grassl, H.: Detection of cloud-top height from backscattered radiances within the oxygen A band. Part 1: Theoretical study, J. Appl. Meteorol., 30, 1245-1259, 1991.

Frey, R. A., Ackerman, S. A., Liu, Y., Strabala, K. I., Zhang, H., Key, J. R., and Wang, X.: Cloud Detection with MODIS. Part I: Improvements in the MODIS Cloud Mask for Collection 5, J. Atmos. Ocean. Tech., 25, 1057-1072, https://doi.org/10.1175/2008JTECHA1052.1, 2008.

Gao, M., Zhai, P.-W., Yang, Y., and Hu. Y.: Cloud remote sensing with EPIC/DSCOVR observations: A sensitivity study with radiative transfer simulations, J. Quant. Spectrosc. Ra., 230, 56-60, https://doi.org/10.1016/j.jqsrt.2019.03.022, 2019.

Geogdzhayev, I. V. and Marshak, A.: Calibration of the DSCOVR EPIC visible and NIR channels using MODIS Terra and Aqua data and EPIC lunar observations, Atmos. Meas. Tech., 11, 359368, https://doi.org/10.5194/amt-11-359-2018, 2018 (data available at: https://doi.org/10.5067/EPIC/DSCOVR/L1B.002).

Grechko, Y. I., Dianov-Klokov, V. I., and Malkov, I. P.: Aircraft measurements of photon paths in reflection and transmission of light by clouds in the $0.76 \mathrm{~mm}$ oxygen band, Atmos. Ocean Phys., 9, 262-265, 1973.

Herman, J., Huang, L., McPeters, R., Ziemke, J., Cede, A., and Blank, K.: Synoptic ozone, cloud reflectivity, and erythemal irradiance from sunrise to sunset for the whole earth as viewed by the DSCOVR spacecraft from the earth-sun Lagrange 1 orbit, Atmos. Meas. Tech., 11, 177-194, https://doi.org/10.5194/amt11-177-2018, 2018 
Karlsson, K.-G. and Håkansson, N.: Characterization of AVHRR global cloud detection sensitivity based on CALIPSO-CALIOP cloud optical thickness information: demonstration of results based on the CM SAF CLARA-A2 climate data record, Atmos. Meas. Tech., 11, 633-649, https://doi.org/10.5194/amt-11-6332018, 2018.

Khlopenkov, K., Duda, D., Thieman, M., Minnis, P., Su, W., and Bedka, K.: Development of multi-sensor global cloud and radiance composites for earth radiation budget monitoring from DSCOVR, Proc. SPIE 10424, Remote Sens., 104240K, Warsaw, 2 October 2017, https://doi.org/10.1117/12.2278645, 2017.

Koelemeijer, R. B. Stammes, A. P., Hovenier, J. W., and de Haan, J. F.: A fast method for retrieval of cloud parameters using oxygen A band measurements from the Global Ozone Monitoring Experiment, J. Geophys. Res., 106, 3475-3490, 2001.

Marshak, A., Herman, J., Szabo, A., Blank, K., Cede, A., Carn, S., Geogdzhayev, I., Huang, D., Huang, L-K, Knyazikhin, Y., Kowalewski, M., Krotkov, N., Lyapustin, A., McPeters, R., Meyer, K., Torres, O., and Yang, Y.: Earth observations from DSCOVR/EPIC instrument, B. Am. Meteorol. Soc., 99, 18291850, https://doi.org/10.1175/BAMS-D-17-0223.1, 2018.

Meyer, K., Yang, Y., and Platnick, S.: Uncertainties in cloud phase and optical thickness retrievals from the Earth Polychromatic Imaging Camera (EPIC), Atmos. Meas. Tech., 9, 1785-1797, https://doi.org/10.5194/amt-9-1785-2016, 2016.

Min, Q. L., Harrison, L. C., Kierdron, P., Berndt, J., and Joseph, E.: A high-resolution oxygen A-band and water vapor band spectrometer, J. Geophys. Res., 109, D02202, https://doi.org/10.1029/2003JD003540, 2004.

Minnis, P., Sun-Mack, S., Young, D. F., Heck, P. W., Garber, D. P., Chen, Y., Spangenberg, D. A., Arduini, R. F., Trepte, Q. Z., Smith, W. L. Jr., Ayers, J. K., Gibson, S. C., Miller, W. F., Chakrapani, V., Takano, Y., Liou, K.-N., Xie, Y., and Yang, P.: CERES Edition-2 cloud property retrievals using TRMM VIRS and Terra and Aqua MODIS data, Part I: Algorithms, IEEE T. Geosci. Remote, 49, 4374-4400, https://doi.org/10.1109/TGRS.2011.2144601, 2011.

Petty, W. G.: A first course in atmospheric radiation, Sundog Pub., ISBN 9780972903318, 2006.

Pirazzini, R.: Surface albedo measurements over Antarctic sites in summer, J. Geophys. Res., 109, D20118, https://doi.org/10.1029/2004JD004617, 2004.

Richardson, M., Leinonen, J., Cronk, H. Q., McDuffie, J., Lebsock, M. D., and Stephens, G. L.: Marine liquid cloud geometric thickness retrieved from OCO-2's oxygen A-band spectrometer, Atmos. Meas. Tech., 12, 1717-1737, https://doi.org/10.5194/amt12-1717-2019, 2019.

Rossow, W. B. and Garder, L. C.: Cloud detection using satellite measurements of infrared and visible radiances for ISCCP, J. Climate, 6, 2341-2369, 1993.

Rothman, L., Gordon, I., Babikov, Y., Barbe, A., Benner, D.C., Bernath, P., Birk, M., Bizzocchi, L., Boudon, V. , Brown, L.R., Campargue, A., Chance, K., Cohen, E. A. , Coudert, L. H., Devi, V. M., Drouin, B. J., Fayt, A.,Flaud, J.-M., Gamache, R. R., Harrison, J. J. , Hartmann, J.-M., Hill, C., Hodges, J. T., Jacquemart, D., Jolly, A., Lamouroux, J., Le Roy, R. J., Li, G., Long, D. A., Lyulin, O. M., Mackie, C. J., Massie, S. T., Mikhailenko, S., Mu“ller, H. S. P., Naumenko, O. V., Nikitin, A. V., Orphal, J., Perevalov, V., Perrin, A., Polovtseva, E. R., Richard, C., Smith,
M. A. H., Starikova, E., Sung, K., Tashkun, S., Tennyson, J. , Toon, G. C., Tyuterev, V. G., and Wagner, G.: The hitran2012 molecular spectroscopic database, J. Quant. Spectrosc. Ra., 130, 4-50, https://doi.org/10.1016/j.jqsrt.2013.07.002, 2013.

Row III, L. W. and Hastings, D. A.: TerrainBase worldwide digital terrain data, release 1.0 NOAA/National Geophysical Data Center, available at: ftp://ftp.ngdc.noaa.gov/Solid_Earth/cdroms/ TerrainBase_94/data/global/tbase/ (last access: 26 March 2020), 1994.

Saunders, R. W. and Kriebel, K. T. : An improved method for detecting clear sky and cloudy radiances from AVHRR data, Int. J. Remote Sens., 9, 123-150, 1988.

Shang, H., Letu, H., Nakajima, T. Y., Wang, Z., Ma, R., Wang, T., Lei, Y., Ji, D., Li, S., and Shi, J.: Diurnal cycle and seasonal variation of cloud cover over the Tibetan Plateau as determined from Himawari-8 new-generation geostationary satellite data, Sci. Rep.-UK, 8, 1105, https://doi.org/10.1038/s41598018-19431-w, 2018.

Stammes, P., Sneep, M., de Haan, J. F., Veefkind, J. P., Wang, P., and Levelt, P. F.: Effective cloud fractions from the Ozone Monitoring Instrument: Theoretical framework and validation, J. Geophys. Res., 113, D16S38, https://doi.org/10.1029/2007JD008820, 2008.

Su, W., Liang, L., Doelling, D. R., Minnis, P., Duda, D. P., Khlopenkov, K. V., Thieman, M., Loeb, N. G., Kato, S., Valero, F. P. J., Wang, H., and Rose, F. G.: Determining the Shortwave Radiative Flux from Earth Polychromatic Imaging Camera, J. Geophys. Res., 123, 11479-11491, https://doi.org/10.1029/2018JD029390, 2018.

Su, W., Minnis, P., Liang, L., Duda, D. P., Khlopenkov, K., Thieman, M. M., Yu, Y., Smith, A., Lorentz, S., Feldman, D., and Valero, F. P. J.: Determining the daytime Earth radiative flux from National Institute of Standards and Technology Advanced Radiometer (NISTAR) measurements, Atmos. Meas. Tech., 13, 429-443, https://doi.org/10.5194/amt-13-429-2020, 2020.

Vasilkov, A., Joiner, J., Spurr, R., Bhartia, P. K., Levelt, P., and Stephens, G.: Evaluation of the OMI cloud pressures derived from rotational Raman scattering by comparisons with other satellite data and radiative transfer simulations, J. Geophys. Res., 113, D15S19, https://doi.org/10.1029/2007JD008689, 2008.

Wang, P., Stammes, P., van der A, R., Pinardi, G., and van Roozendael, M.: FRESCO+: an improved $\mathrm{O}_{2}$ A-band cloud retrieval algorithm for tropospheric trace gas retrievals, Atmos. Chem. Phys., 8, 6565-6576, https://doi.org/10.5194/acp-8-6565-2008, 2008.

Wang, T., Fetzer, E. J., Wong, S., Kahn, B. H., and Yue, Q.: Validation of MODIS cloud mask and multilayer flag using CloudSatCALIPSO cloud profiles and a cross-reference of their cloud classifica- tions, J. Geophys. Res.-Atmos., 121, 11620-11635, https://doi.org/10.1002/2016JD025239, 2016.

Warren, S. G.: Optical properties of snow, Rev. Geophys., 20, 6789, 1982.

Yang, P., Bi, L., Baum, B. A., Liou, K.-N., Kattawar, G. W., Mishchenko, M. I., and Cole, B.: Spectrally Consistent Scattering, Absorption, and Polarization Properties of Atmospheric Ice Crystals at Wavelengths from 0.2 to $100 \mu \mathrm{m}$, J. Atmos. Sci., 70, 330-347, https://doi.org/10.1175/JAS-D-12-039.1, 2013.

Yang, Y., Di Girolamo, L., and Mazzoni, D.: Selection of the automated thresholding algorithm for Multi-angle Imag- 
ing SpectroRadiometer Radiometric Camera-by-Camera Cloud Mask over land, Remote Sens. Environ., 107, 159-171, https://doi.org/10.1016/j.rse.2006.05.020, 2007.

Yang, Y., Marshak, A., Mao, J., Lyapustin, A., and Herman, J.: A Method of Retrieving Cloud Top Height and Cloud Geometrical Thickness with Oxygen A and B bands for the Deep Space Climate Observatory (DSCOVR) Mission: Radiative Transfer Simulations, J. Quant. Spectrosc. Ra., 122, 141149, https://doi.org/10.1016/j.jqsrt.2012.09.017, 2013.

Yang, Y., Meyer, K., Wind, G., Zhou, Y., Marshak, A., Platnick, S., Min, Q., Davis, A. B., Joiner, J., Vasilkov, A., Duda, D., and Su, W.: Cloud products from the Earth Polychromatic Imaging Camera (EPIC): algorithms and initial evaluation, Atmos. Meas. Tech., 12, 2019-2031, https://doi.org/10.5194/amt-12-2019-2019, 2019 (data available at: https://doi.org/10.5067/EPIC/DSCOVR/L2_Cloud_01).
Zhai, P., Hu, Y., Trepte, C. R., and Lucker, P. L.: A vector radiative transfer model for coupled atmosphere and ocean systems based on successive order of scattering method, Opt. Express 17, 2057 2079, 2009.

Zhai, P., Hu, Y., Chowdhary, J., Trepte, C. R., Lucker, P. L., and Josset, D. B.: A vector radiative transfer model for coupled atmosphere and ocean systems with a rough interface, J. Quant. Spectrosc. Ra., 111, 1025-1040, 2010.

Zhao, M. and Wang, Z.: Comparison of Arctic clouds between European Center for Medium-Range Weather Forecasts simulations and Atmospheric Radiation Measurement Climate Research Facility long-term observations at the North Slope of Alaska Barrow site, J. Geophys. Res., 115, D23202, https://doi.org/10.1029/2010JD014285, 2010. 